\title{
A AQUISIÇÃO DO PADRÃO ACENTUAL E O INPUT
}

Raquel Santana Santos

(USP/CNPq)

\section{RESUMO}

A maioria dos estudos lidando com os padrões prosódicos das primeiras palavras, nas últimas décadas, encontraram uma tendência trocaica (forte-fraco) nas línguas. Uma linha de explicação para esta tendência é que os troqueus resultam de um valor default 'esquerda' para o parâmetro do núcleo do pé (e.g. DRESHER 1992, FIKKERT 1994). Entretanto, como muitos destes estudos discutem línguas que são trocaicas na forma adulta (e.g. inglês, holandês), é difícil separar se os troqueus iniciais são devidos ao valor default ou se refletem o padrão da língua alvo. Além disso, alguns estudos têm demonstrado que nem sempre as crianças apresentam uma tendência trocaica (e.g. DEMUTH 1996). O português brasileiro se torna então uma língua muito interessante a se analisar, pois, de um lado, apresenta mais troqueus do que iambos (fraco-forte) na fala adulta; e por outro, as crianças começam produzindo mais iambos do que troqueus (e.g. SANTOS 2001, 2007, BONILHA 2005, BAIA 2008). Alguém poderia argumentar que esta tendência iâmbica inesperada nos dados iniciais de português é consistente com a frequência de palavras multissilábicas na língua ambiente (e.g. KEHOE 1999, ROARK \& DEMUTH 2000, PRIETO 2006). Neste artigo, colocamos esta explicação alternativa à prova, analisando dados de 2 crianças adquirindo português brasileiro, bem como de seus interlocutores. Se a análise defendendo a influência da fala dirigida à criança (FDC) estiver correta, deveríamos esperar encontrar mais iambos do que troqueus em FDC, dado que análises prévias de dados de crianças adquirindo português brasileiro encontraram uma tendência iâmbica. Os resultados, no entanto, mostram que FDC apresentam um padrão distribucional diferente da fala adulta, mas ainda assim há mais troqueus que iambos. Além 
disso, a produção infantil apresenta uma distribuição de padrões prosódicos diferente do FDC. Logo, FDC não pode explicar os padrões prosódicos iniciais do português brasileiro. Adicionalmente, os resultados mostram que as crianças não estão evitando nenhum padrão acentual específico na sua seleção lexical, nem evitando algum padrão na sua produção. Em suma, nossos resultados claramente descartam a hipótese de que os padrões prosódicos infantis refletem a distribuição dos padrões prosódicos em FDC.

PALAVRAS-CHAVE: aquisição de padrões de acento lexical, input, frequência de uso

\section{Introdução}

A maioria dos estudos que lidam com o arcabouço prosódico-acentual das primeiras palavras, nas últimas décadas, encontraram uma tendência trocaica (forte fraco $-\mathrm{sw})^{1}$ em várias línguas. ${ }^{2}$ Uma linha de explicação para esta tendência é que os troqueus resultam de um valor default para o parâmetro do núcleo do pé marcado como esquerda (cf. DRESHER 1992, FIKKERT 1994). No entanto, como muitos destes estudos discutem línguas que são trocaicas na forma adulta (e.g. inglês, holandês), é difícil separar se os troqueus iniciais são devidos a um valor default ou se já são reflexo do padrão da língua alvo. Além disso, alguns estudos não encontraram nenhuma tendência inicial (e.g. DEMUTH 1996, ROSE \& CHAMPDOIZEAU 2008). Neste sentido, é interessante analisar o português brasileiro, já que, embora apresente na fala adulta mais troqueus, as crianças começam produzindo formas iâmbicas (fraca forte - ws). Atualmente, muitos estudos translinguísticos argumentam que a emergência dos padrões prosódicos pode ser influenciada pelo input.

A discussão sobre a influência do input na aquisição da linguagem infantil não é nova. Nos anos 1970 e 1980, a discussão voltava-se principalmente para as características da fala dirigida à criança (Child Directed Speech, Motherese, Baby Talk Register, doravante FDC). Nestas décadas, a discussão centrava-se mais em descobrir se as características deste tipo de fala poderiam ser facilitadores do processo de aquisição, como ilustra a Motherese Hypothesis, de Gleitman, Newport \& Gleitman (1984:45): "Those special restrictive properties of caretaker speech play a causal role in language acquisition." De acordo com os autores, na FDC há uma restrição nas escolhas entre as estruturas e conteúdos permitidos na fala 
adulta. Na forma forte da hipótese, estas escolhas são um requisito para a aprendizagem, enquanto em sua forma fraca, há uma correlação inversa entre o uso de motherese e a rapidez e quantidade de erros pela criança no processo de aquisição.

Lust (2006) resume da seguinte forma as razões pelas quais essa hipótese não se mantém: se a criança ficasse restrita apenas às estruturas da fala que lhe é dirigida, ela não conseguiria aprender a língua adulta (que apresenta outras caraterísticas); as características da FDC não modificam aspectos fundamentais da fala adulta, de modo que pudessem ser um facilitador; este tipo de fala não é universal - há grupos que a utilizam, outros não; as transformações da fala adulta para a FDC nem sempre são dirigidas por regras, têm caráter muitas vezes idiossincrático, e não levam necessariamente a estruturas mais simples; as crianças expostas a uma fala modificada que lhe é dirigida também estão expostas à fala adulta, de forma que não é possível concluir com certeza de que este tipo de fala afeta o processo de aquisição; a hipótese de que a FDC é mais simples levaria a criança a ter mais hipóteses a testar sobre a língua que está adquirindo.

Atualmente, uma volta a essa discussão se dá quando se levanta a hipótese de que a criança leva em conta padrões do input e que estes padrões afetam o processo de aquisição da linguagem. Por exemplo, segundo Pierrehumbert (2001:2), a assunção dos modelos de uso é que "frequency information plays an intrinsic role in the [linguistic] system because it is implicitly encoded by the very nature of the memory system."

Os modelos de uso não necessariamente levam em conta a FDC, mas se estamos falando de influência de padrões, devemos então observar se os padrões distribucionais deste tipo de fala não afetam o processo de aquisição. Este artigo revisita a aquisição dos padrões acentuais das palavras em português brasileiro, tendo por objetivo observar se o percurso de aquisição dos diferentes padrões em português espelha os padrões mais produtivos da fala adulta e da FDC. Para tanto, volta-se aos dados das crianças e de suas mães, analisadas em Santos (2007), para os dados infantis e de FDC; e para a frequência de distribuição dos padrões na fala adulta, utiliza-se Cintra (1997).

Para a condução desta discussão, este artigo está organizado da seguinte maneira: na primeira seção, resume-se a distribuição dos padrões acentuais no português brasileiro adulto e na FDC. Na segunda seção, trazemos os resultados sobre aquisição do português brasileiro no que se refere a emergência e distribuição de padrões. A terceira seção descreve a 
metodologia e a quarta e quinta seções trazem os resultados e discussão. Na sexta seção são apresentadas as considerações finais.

\section{0 padrão acentual no léxico do português bra-} sileiro

Antes de discutir a distribuição do padrão acentual no léxico do português brasileiro, cumpre chamar a atenção que na literatura sobre a atribuição acentual em verbos e não-verbos é consensual que as duas classes são acentuadas com algoritmos/regras diferentes, com um papel muito forte da morfologia no primeiro caso (cf. e.g. Bisol 1992, Lee 1995). Como veremos, diferentes trabalhos sobre a distribuição dos padrões acentuais analisam diferentes conjuntos: ou apenas não-verbos, ou verbos e não-verbos.

A primeira distinção a se fazer, quando se discute a distribuição dos padrões acentuais, é se a análise está sendo feita por types ou tokens. A frequência de ocorrência (tokens) leva em conta todas as produções de uma mesma palavra, enquanto que a frequência de tipo (type) leva em conta apenas uma produção. No caso da frequência por tipos, se ela é feita tendo como base dicionários, ela trará palavras mais e menos frequentes da língua, igualmente. No caso de se analisar textos escritos ou orais, ela estará mais próxima da frequência de uso da fala. Este é um cuidado importante a se ter quando se tenta explicar a aquisição da linguagem, já que, se se assume que a frequência afeta a aquisição, então deve-se analisar a frequência a que a criança está exposta.

Todos os trabalhos sobre o padrão acentual do português brasileiro apontam um favorecimento ao acento na penúltima sílaba - cf. Tabela 1 . Viaro \& Guimarães-Filho (2007) apresentam um levantamento da distribuição dos padrões acentuais de palavras do Dicionário Houaiss. Trata-se de uma análise por tipo, em que trazemos aqui os resultados da base BES, isto é, aquela em que os autores consideraram casos de adição de fonemas e fusão de sílabas. Benevides (2016) apresenta a distribuição dos padrões acentuais no corpus ABG, composto por textos escritos e orais. O corpus escrito é composto por artigos científicos, textos jornalísticos e postagem em blogs, enquanto o corpus de fala é proveniente de entrevistas sociolinguísticas (Projeto SP2010 - MENDES 2010, MENDES \& OUSHIRO 2012; C-Oral-Brasil - RASO \& MELLO 2012; Iboruna - GONÇALVES 2014). A autora aponta a frequência por ocorrência e tipo no corpus, mas 
a distribuição dos padrões acentuais é feita para a frequência por tipo.

Cintra (1997) faz um levantamento em textos escritos, por ocorrência. Trazemos aqui os resultados da distribuição levando em conta apenas os vocábulos acentuados. Cantoni (2013) faz um levantamento da frequência de tipo e de ocorrência no banco de dados do Projeto ASPA, um corpus de padrões sonoros. Como o objetivo era analisar a posição acentual, em seu trabalho os monossílabos foram excluídos do cálculo. Aqui trazemos os resultados para não-verbos.

\begin{tabular}{|c|c|c|c|c|c|c|}
\hline & & monossílabos & oxítonos & paroxítonos & proparoxítonos & $4^{\mathrm{a}}$.sílaba \\
\hline \multirow{4}{*}{ Type } & Albano 2001 & $0.3 \%$ & $35 \%$ & $53.5 \%$ & & \\
\hline & $\begin{array}{l}\text { Viaro \& Guimarães } \\
\text { Filho } 2007\end{array}$ & $0.3-0.5 \%$ & $25 \%$ & $62 \%$ & $12 \%$ & $0.4 \%$ \\
\hline & Cantoni 2013 & -- & $18.2 \%$ & $67.1 \%$ & $14.6 \%$ & -- \\
\hline & Benevides 2016 & $1.6 \%$ & $25.9 \%$ & $68.5 \%$ & $4 \%$ & $0.4 \%$ \\
\hline \multirow[t]{3}{*}{ Token } & Cintra 1997 & $12 \%$ & $18 \%$ & $63 \%$ & $7 \%$ & \\
\hline & $\begin{array}{l}\text { Cantoni } 2013 \text { - alta } \\
\text { frequência }\end{array}$ & & $23 \%$ & $64.5 \%$ & $12.5 \%$ & \\
\hline & $\begin{array}{l}\text { Cantoni } 2013- \\
\text { baixa frequência }\end{array}$ & & $14.7 \%$ & $67.2 \%$ & $18.1 \%$ & \\
\hline
\end{tabular}

Tabela 1: distribuição dos padrões acentuais no PB por autor

Segundo Cantoni, os três padrões acentuais (oxítono, paroxítono e proparoxítono) apresentam uma distribuição significativamente diferente tanto para análise por tipos $((\chi 2[2]=40.182, \mathrm{p}<0,001)$ quando por ocorrência. Seguindo Bybee \& Hopper (2001), Cantoni (2013) chama a atenção de que a frequência de tipo afeta a produção de padrões. Por outro lado, palavras com frequência de ocorrência devem ser analisadas quanto à baixa ou alta produtividade: palavras com baixa produtividade são mais suscetíveis a padrões da frequência de tipo do que palavras de alta produtividade (que poderiam, mais facilmente, se desviar dos padrões de produção). Assim, a autora observa se há uma diferente distribuição dos padrões acentuais a depender da frequência e os resultados apontam que a diferença entre os padrões é significativa nos dois casos (em palavras de alta frequência: $\chi^{2}[2]=164, \mathrm{p}<0,001$; nos casos de baixa frequência: $\chi 2[2]=5.562, \mathrm{p}<0,001)$.

Araújo, Guimarães-Filho, Oliveira \& Viaro (2007) levantam a distribuição dos padrões acentuais levando em conta a frequência de ocorrência (uso) e usando como fonte a base de páginas em português do Google. Como se observa na Tabela 2, há uma grande diferença na dis- 
tribuição dos monossílabos e dos proparoxítonos - os proparoxítonos se concentram nas palavras raras e os monossílabos nas palavras frequentes.

\begin{tabular}{|l|ll|l|l|}
\hline & \multicolumn{4}{|c|}{ Quartis de Frequência de Uso } \\
\cline { 2 - 5 } & raras & incomuns & comuns & frequentes \\
\hline Toda a base & $27.5 \%$ & $26.3 \%$ & $23.7 \%$ & $22.6 \%$ \\
\hline Monossílabos & $0 \%$ & $0.2 \%$ & $4.4 \%$ & $95.4 \%$ \\
\hline Oxítonas & $21.1 \%$ & $27.2 \%$ & $26.1 \%$ & $25.6 \%$ \\
\hline Paroxítonas & $26.3 \%$ & $26.4 \%$ & $24.2 \%$ & $23.1 \%$ \\
\hline proparoxítonas & $47.5 \%$ & $24.8 \%$ & $16.4 \%$ & $11.4 \%$ \\
\hline
\end{tabular}

Tabela 2: Distribuição estatistica da frequência de uso de Araujo et al (2007: Tabela 3)

A discussão sobre as diferentes consequências de uma palavra ser mais ou menos frequente por ocorrência levanta a questão das diferenças dessa classificação nas diferentes interações de fala. Especificamente para o caso da aquisição da linguagem, devemos então nos perguntar se há uma diferente distribuição dos padrões acentuais na fala a que a criança está exposta, a Child Directed Speech (FDC). A FDC apresenta uma série de características linguísticas: as sentenças são mais curtas, com muitas repetições, e uso de estruturas coordenadas assindéticas; há muito uso de hipocorismos e verbos compostos; prosodicamente, os contornos entoacionais são mais exagerados, produzidos com uma frequência (pitch) mais alta e com velocidade menor. Fonologicamente, há muitas reduções de encontros consonantais, substituições de segmentos, reduplicações (cf. FERGUSON 1978).

As palavras familiares, do léxico infantil, são quase todas oxítonas em português brasileiro: xixi, cocô, nenê, papá (cf. STOEL-GAMON 1976, BAIA 2010). Por outro lado, muitas das características da FDC modificam o padrão acentual - como por exemplo, a alta quantidade de diminutivos, que transformam todos os diferentes padrões acentuais em paroxítonos - cf. (1):

(1) a. Oxítonas: café, colher >> cafezinho, colherzinha

b. Paroxítonas: casa, móvel $>$ casinha, movelzinho c. Proparoxítonas: príncipe, ônibus $\gg>$ principezinho, onibuzinho

Além disso, estudos reportam que o grau de FDC varia entre os cuidadores (pais, babás, etc - e.g. HOFF-GINSBERG 1991; ROWE, COKER \& PAN 2004); assim, no caso de uma análise da influência da 
frequência do padrão para a criança, o ideal é comparar a fala infantil com a fala a que a criança está exposta.

Em suma, ao se discutir a influência da frequência de uso dos padrões no processo de aquisição, deve-se atentar para que seja observada a frequência dos padrões a que a criança está exposta - muito embora, como aponta Lust (2006), não seja possível separar completamente os resultados já que as crianças estão sempre expostas à fala adulta também.

\section{Trabalhos sobre Aquisição do Padrão Acentual}

Nas últimas décadas, diversos trabalhos têm tratado da aquisição do padrão acentual do português brasileiro, dentro dos mais diversos quadros teóricos. Scarpa (1997) e Santos (2001) defendem que as primeiras proeminências infantis não são de acento lexical, mas de acento entoacional. Em português brasileiro, a proeminência entoacional recai sobre a sílaba tônica mais à direita do enunciado (enunciados sem foco ou tópico). As crianças utilizam este padrão, de proeminência mais à direita para marcar a proeminência das palavras. Como no início do processo de aquisição as palavras são normalmente dissílabas, a criança acaba com um constituinte binário com cabeça à direita - um iambo (ws). Segundo Santos (2001), posteriormente, quando as crianças começam a trabalhar com a morfologia, elas modificam o domínio do acento - da palavra para o radical. As autoras não fazem uma análise quantitativa dos dados. Santos (2007), numa visão gerativista de princípios e parâmetros, argumenta que o padrão iâmbico ocorre logo no início do processo de aquisição porque o iambo é a unidade constitutiva do acento do português brasileiro (seguindo LEE 1995) e a marcação do parâmetro de núcleo do pé (que define se a unidade na língua é um iambo ou troqueu (constituinte binário com cabeça à esquerda: sw)) deve ocorrer bem inicialmente, para que a criança possa produzir dissílabos (já que é um princípio que toda palavra com mais de uma sílaba deve ter uma sílaba proeminente). A autora ainda defende que o parâmetro de núcleo do pé não apresenta um valor default, o que permitiria explicar por que línguas diferentes apresentam padrões acentuais iniciais diferentes (já que o holandês, por exemplo, apresenta um padrão trocaico inicial - cf. FIKKERT 1994).

Baia (2008) faz uma análise comparando resultados de um corpus formado por dados naturalísticos com um experimento e chega à conclusão de que o tipo de coleta afeta os resultados, já que houve mais oxítonos 
nos dados naturalísticos do que nos experimentais. Chamamos atenção aqui para os resultados dos dados naturalísticos, para que possamos comparar com os outros estudos em português brasileiro. O corpus é constituído de dados de 3 crianças (M., A. e G.) entre 0;9 e 2;0 anos. Os resultados gerais são apresentados na Tabela 3. Como se nota, os resultados apontam para diferentes padrões, mas em comum tem-se que nenhum deles apresenta a mesma distribuição que na fala adulta. Veja que a menor produção de monossílabos, por A., é de $22 \%$, ao passo que na fala adulta, a maior quantidade de monossílabos foi encontrada por Cintra, mas $12 \%$.

\begin{tabular}{|l|l|l|l|l|}
\hline & monossílabo & oxítono & paroxítono & Total \\
\hline M & $759(38.5 \%)$ & $572(29 \%)$ & $641(32.5 \%)$ & 1973 \\
\hline A & $154(22 \%)$ & $227(32.5 \%)$ & $318(45.5 \%)$ & 699 \\
\hline G & $220(23.4 \%)$ & $374(39.8 \%)$ & $345(36.7 \%)$ & 939 \\
\hline
\end{tabular}

Tabela 3: distribuição dos padrões acentuais nos sujeitos de Baia (2008)

Porém, quando observamos os resultados ao longo do desenvolvimento, o padrão que emerge é diferente. A Tabela 4 traz os resultados ao longo do período analisado, mas Baia não traz os resultados de produção de monossílabos. ${ }^{3}$

\begin{tabular}{|l|l|l|l|l|l|l|}
\hline \multirow{2}{*}{ idade } & \multicolumn{2}{|c|}{$\mathrm{M}^{3}$} & \multicolumn{2}{c|}{$\mathrm{A}$} & \multicolumn{2}{c|}{$\mathrm{G}$} \\
\cline { 2 - 7 } & oxítono & paroxítono & oxítono & paroxítono & oxítono & paroxítono \\
\hline $0 ; 9$ & 0 & 0 & $2(100 \%)$ & 0 & 0 & 0 \\
\hline $0 ; 10$ & $9(82 \%)$ & $2(18 \%)$ & $10(71 \%)$ & $4(29 \%)$ & $3(50 \%)$ & $3(50 \%)$ \\
\hline $0 ; 11$ & $6(75 \%)$ & $1(12.5 \%)$ & 0 & $2(100 \%)$ & $11(100 \%)$ & 0 \\
\hline $1 ; 0$ & $10(83 \%)$ & $2(17 \%)$ & $1(100 \%)$ & 0 & $8(57 \%)$ & $6(43 \%)$ \\
\hline $1 ; 1$ & $10(53 \%)$ & $9(47 \%)$ & $3(75 \%)$ & $1(25 \%)$ & $17(55 \%)$ & $14(45 \%)$ \\
\hline $1 ; 2$ & $24(92 \%)$ & $4(8 \%)$ & $4(67 \%)$ & $2(33 \%)$ & $6(21 \%)$ & $22(79 \%)$ \\
\hline $1 ; 3$ & $18(82 \%)$ & $4(18 \%)$ & $4(44 \%)$ & $5(56 \%)$ & $17(47 \%)$ & $19(53 \%)$ \\
\hline $1 ; 4$ & $46(92 \%)$ & $4(8 \%)$ & $5(42 \%)$ & $7(58 \%)$ & $9(26 \%)$ & $26(74 \%)$ \\
\hline $1 ; 5$ & $29(91 \%)$ & $3(9 \%)$ & $5(63 \%)$ & $3(37 \%)$ & $25(68 \%)$ & $12(32 \%)$ \\
\hline $1 ; 6$ & $52(45 \%)$ & $62(54 \%)$ & $16(100 \%)$ & 0 & $19(48 \%)$ & $21(52 \%)$ \\
\hline $1 ; 7$ & $71(47 \%)$ & $81(53 \%)$ & $17(55 \%)$ & $14(45 \%)$ & $46(70 \%)$ & $20(30 \%)$ \\
\hline $1 ; 8$ & $53(41 \%)$ & $76(59 \%)$ & $26(32 \%)$ & $55(68 \%)$ & $59(69 \%)$ & $27(31 \%)$ \\
\hline $1 ; 9$ & $63(36 \%)$ & $112(64 \%)$ & $48(38 \%)$ & $79(62 \%)$ & $25(35 \%)$ & $46(65 \%)$ \\
\hline $1 ; 10$ & $44(32 \%)$ & $93(68 \%)$ & $58(48 \%)$ & $71(55 \%)$ & $54(76 \%)$ & $17(24 \%)$ \\
\hline $1 ; 11$ & $52(40 \%)$ & $78(60 \%)$ & $10(27 \%)$ & $27(73 \%)$ & $49(34 \%)$ & $79(66 \%)$ \\
\hline $2 ; 0$ & $85(43 \%)$ & $112(56.5 \%)$ & $18(27 \%)$ & $48(73 \%)$ & $35(51 \%)$ & $33(49 \%)$ \\
\hline
\end{tabular}

Tabela 4: Distribuição dos padrões acentuais dos sujeitos de Baia (2008) ao longo do desenvolvimento

O primeiro fator a se salientar é que, quando distribuídos ao longo do tempo analisado, os dados tornam-se por vezes em muito baixa quantidade, de forma que as quantidades (e principalmente as percentagens) 
devem ser vistas com muita cautela. Por exemplo, A, aos 0;9 meses, tem $100 \%$ de produção de oxítonos, mas isso equivale a apenas 2 produções. De acordo com os resultados gerais, $M$ produz uma quantidade total muito parecida de paroxítonos e oxítonos. No entanto, o que vemos é uma forte prevalência de oxítonos até os 1;5; um equilíbrio entre os dois padrões entre $1 ; 6$ e 1;8, e depois uma maior produção de paroxítonos a partir de 1;9. No caso de A., os valores totais apontam para mais paroxítonos do que oxítonos. Porém, até $1 ; 2$ tem-se mais oxítonos, que voltam a prevalecer aos $1 ; 5$ e $1 ; 6$. Aos $1 ; 3$ e 1;4 e novamente aos $1 ; 7$, tem-se um equilíbrio na distribuição de padrões. A partir de 1;8 ocorrem mais paroxítonos que oxítonos. O caso de G., na soma total, é parecido com o de M., com uma distribuição equilibrada de paroxítonos e oxítonos. No entanto, não se pode dizer sequer que há um padrão sendo privilegiado em determinados momentos. O que se observa é muitas vezes um equilíbrio entre as duas formas, em outras uma prevalência de oxítonos - mesmo quando as outras crianças já apresentavam um predomínio de paroxítonos, que só são maioria em duas sessões.

Baia (2013) retoma os dados de Baia (2008) e dá-lhes uma nova interpretação. Seguindo os pressupostos da Whole Word/Templatic Phonology (e.g. WATERSON 1971, VIHMAN \& KEREN-PORTNOY 2013), a autora defende que as crianças obedecem a templates (modelos, arcabouços) durante o processo de aquisição. Os templates podem ser inferidos pelas produções modificadas das crianças. A autora persegue a hipótese de que "quando não houver evidência de influência de balbucio produzido pelas crianças em estudo, os templates apresentarão características da tipologia da língua alvo" (BAIA, 2013, p.197) - atestada em trabalhos como Vihman \& Velleman (2002), Wauquier \& Yamaguchi (2012). O Quadro 1 traz a análise da autora para cada sessão analisada (adaptado de BAIA 2013, Quadro 41, pag. 189): 


\begin{tabular}{|c|c|c|c|}
\hline Idade & $\mathrm{M}$ & $\bar{A}$ & G \\
\hline $0 ; 9$ & - & $\begin{array}{l}\mathrm{C}_{1} \mathrm{~V}_{1} .{ }^{\prime} \mathrm{C}_{1} \mathrm{~V}_{1} \\
\mathrm{C}_{1} \mathrm{~V}_{1}, \mathrm{C}_{1} \mathrm{C}_{2} \\
\end{array}$ & $\overline{----}$ \\
\hline $0 ; 10$ & $\begin{array}{l}\mathrm{C}_{1} \mathrm{~V}_{1}, \mathrm{C}_{1} \mathrm{~V}_{1} \\
\mathrm{C}_{1} \mathrm{~V}_{1}, \mathrm{C}_{1} \mathrm{~V}_{2}\end{array}$ & $\begin{array}{l}\mathrm{C}_{1} \mathrm{~V}_{1} \cdot{ }^{\prime} \mathrm{C}_{1} \mathrm{~V}_{1} \\
\mathrm{C}_{1} \mathrm{~V}_{1} \cdot{ }^{\prime} \mathrm{C}_{1} \mathrm{~V}_{2}\end{array}$ & -- \\
\hline $0 ; 11$ & $\begin{array}{l}\mathrm{C}_{1} \mathrm{~V}_{1} \cdot{ }^{\prime} \mathrm{C}_{1} \mathrm{~V}_{1} \\
\mathrm{C}_{1} \mathrm{~V}_{1} \cdot{ }^{\prime} \mathrm{C}_{1} \mathrm{~V}_{2}\end{array}$ & V. 'CV & $\mathrm{CV}$ \\
\hline $1 ; 0$ & -- & - & -- \\
\hline $1 ; 1$ & -- & - & $\begin{array}{l}\mathrm{C}_{1} \mathrm{~V}_{1} \cdot{ }^{\prime} \mathrm{C}_{1} \mathrm{~V}_{1} \\
\mathrm{C}_{1} \mathrm{~V}_{1} \cdot \mathrm{C}_{1} \mathrm{C}_{2}\end{array}$ \\
\hline $1 ; 2$ & $\mathrm{CV}$ & -- & V.CV \\
\hline $1 ; 3$ & $\mathrm{CV}$ & $\begin{array}{l}\mathrm{C}_{1} \mathrm{~V}_{1} \cdot{ }^{\prime} \mathrm{C}_{1} \mathrm{~V}_{1} \\
\mathrm{C}_{1} \mathrm{~V}_{1} \cdot \mathrm{C}^{\prime} \mathrm{C}_{1} \mathrm{~V}_{2}\end{array}$ & $\begin{array}{l}\mathrm{C}_{1} \mathrm{~V}_{1} \cdot \mathrm{C}^{\prime} \mathrm{C}_{1} \mathrm{~V}_{1} \\
\mathrm{C}_{1} \mathrm{~V}_{1} \cdot \mathrm{C}_{1} \mathrm{C}_{2}\end{array}$ \\
\hline $1 ; 4$ & $\begin{array}{l}\mathrm{C}_{1} \mathrm{~V}_{1}{ }^{\prime} \mathrm{C}_{1} \mathrm{~V}_{1} \\
\mathrm{C}_{1} \mathrm{~V}_{1} . \mathrm{C}_{1} \mathrm{~V}_{2} \\
\end{array}$ & V. CV & $\begin{array}{l}\mathrm{C}_{1} \mathrm{~V}_{1} \cdot \mathrm{C}^{\prime} \mathrm{C}_{1} \mathrm{~V}_{1} \\
\mathrm{C}_{1} \mathrm{~V}_{1} \cdot \mathrm{C}_{1} \mathrm{~V}_{2}\end{array}$ \\
\hline $1 ; 5$ & -- & $\begin{array}{l}\mathrm{C}_{1} \mathrm{~V}_{1} \cdot \mathrm{C}_{1} \mathrm{~V}_{1} \\
\mathrm{C}_{1} \mathrm{~V}_{1} . \mathrm{C}_{1} \mathrm{~V}_{2}\end{array}$ & $\begin{array}{l}\mathrm{C}_{1} \mathrm{~V}_{1} \cdot \mathrm{C}_{1} \mathrm{C}_{1} \\
\mathrm{C}_{1} \mathrm{~V}_{1} \cdot \mathrm{C}_{1} \mathrm{C}_{2}\end{array}$ \\
\hline $1 ; 6$ & -- & $\begin{array}{l}\mathrm{C}_{1} \mathrm{~V}_{1} \cdot{ }^{\prime} \mathrm{C}_{1} \mathrm{~V}_{1} \\
\mathrm{C}_{1} \mathrm{~V}_{1} \cdot{ }^{\prime} \mathrm{C}_{1} \mathrm{~V}_{2} \\
\end{array}$ & $\begin{array}{l}\mathrm{C}_{1} \mathrm{~V}_{1} \cdot{ }^{\prime} \mathrm{C}_{1} \mathrm{~V}_{1} \\
\mathrm{C}_{1} \mathrm{~V}_{1} \cdot \mathrm{C}_{1} \mathrm{~V}_{2}\end{array}$ \\
\hline $1 ; 7$ & -- & - & $\begin{array}{l}\mathrm{C}_{1 \text { (velar) }} \mathrm{V}_{1} \cdot{ }^{\prime} \mathrm{C}_{1 \text { (velar) }} \mathrm{V}_{1} \\
\mathrm{C}_{1 \text { (velar) }} \mathrm{V}_{1}, \mathrm{C}_{1 \text { (velar) }} \mathrm{V}_{2}\end{array}$ \\
\hline $1 ; 8$ & -- & ${ }^{\prime} \mathrm{C}_{1} \mathrm{~V}_{1} \cdot \mathrm{C}_{2} \mathrm{~V}_{2}$ & $\begin{array}{l}\mathrm{C}_{1} \mathrm{~V}_{1} \cdot{ }^{\prime} \mathrm{C}_{1} \mathrm{~V}_{1} \\
\mathrm{C}_{1} \mathrm{~V}_{1} \cdot \mathrm{C}_{1} \mathrm{~V}_{2}\end{array}$ \\
\hline $1 ; 9$ & -- & - & $\begin{array}{l}\mathrm{C}_{1} \mathrm{~V}_{1} \cdot \mathrm{C}_{1} \mathrm{~V}_{1} \\
\mathrm{C}_{1} \mathrm{~V}_{1} \cdot \mathrm{C}_{1} \mathrm{~V}_{2}\end{array}$ \\
\hline $1 ; 10$ & -- & -- & $\begin{array}{l}\mathrm{C}_{1} \mathrm{~V}_{1} \cdot \mathrm{C}_{1} \mathrm{~V}_{1} \\
\mathrm{C}_{1} \mathrm{~V}_{1} \cdot \mathrm{C}_{1} \mathrm{~V}_{2}\end{array}$ \\
\hline $1 ; 11$ & -- & - & -- \\
\hline $2 ; 0$ & & -- & -- \\
\hline
\end{tabular}

Quadro 1: distribuição dos templates prosódicos ao longo do desenvolvimento para os sujeitos de Baia (2008)

Como se pode observar, os templates sugeridos pela autora apontam - exceto por aquele que ocorre aos 1;8 para A. - para uma produção com acento final. A autora então conclui que "essa hipótese é confirmada embora ainda seja preciso verificar em um estudo futuro o modelo acentual nos dados de G. sem o template reduplicado com acento final. Diferentemente de G., M. e A. passaram a produzir mais paroxítonos e essa foi a tendência dos dados gerais porque é o padrão acentual predominante na língua alvo." (BAIA, 2013, p.197). Em suma, os resultados de Baia não diferem daqueles já encontrados (de uma tendência inicial para a produção de acento final), mas a autora sugere que estes emergem devido a templates. No entanto, há que se perguntar por que estes templates fogem do padrão de acentuação da língua alvo. Uma vez que a autora investiga encontrar os templates das palavras quando o balbucio deixa de influenciar as produções, a pergunta desloca-se então para 'por que o balbucio apresenta uma proeminência final?'. 
Bonilha (2005) discute a produção da pauta acentual por uma criança, entre 1;1 e 2;3. Como a autora está interessada na aquisição acentual, e há análises sobre o português que defendem que esta língua é sensível ao peso silábico (cf. BISOL 1992), ela analisa os dados levando em conta a estrutura silábica. Segundo a autora, as formas iâmbicas e trocaicas são produzidas corretamente desde cedo e somente palavras trocaicas geradas por acento marcado (aquelas com a sílaba final pesada) surgem mais tardiamente. A Tabela 5 abaixo (BONILHA 2005, Quadro 17) mostra que, nos dados da autora, há mais tentativas de produção de paroxítonas do que de oxítonas. Não há informações quantitativas sobre como as formas que não foram produzidas de acordo com o alvo foram produzidas. Chama atenção também a baixa quantidade de oxítonos produzidos. Mesmo alcançando o percentual de produção satisfatório, deve-se ter em mente que são muito poucos dados para que possamos afirmar haver uma tendência (por exemplo, até 1;4.9, as oxítonas leves somam 6 possibilidades).

\begin{tabular}{|l|l|l|l|l|l|l|l|l|l|l|l|}
\hline \multirow{2}{*}{ Idade } & \multicolumn{3}{|c|}{ acento não marcado } & \multicolumn{6}{|c|}{ acento marcado } \\
\cline { 2 - 11 } & paroxítona leve & oxítona pesada & paroxítona pesada & \multicolumn{2}{|l|}{ oxítona leve } & \multicolumn{3}{|c|}{ proparoxítona } \\
\cline { 2 - 11 } & Pos & Ocor & Pos & Ocor & Pos & Ocor & Pos & Ocor & Pos & Ocor \\
\hline $1: 1: 22$ & 7 & 6 & 5 & 1 & $*$ & $*$ & 1 & 1 & $*$ & $*$ \\
\hline $1: 3: 10$ & 11 & 8 & 2 & 0 & $*$ & $*$ & 3 & 3 & $*$ & $*$ \\
\hline $1: 3: 24$ & 8 & 6 & 1 & 1 & $*$ & $*$ & 1 & 1 & $*$ & $*$ \\
\hline $1: 4: 09$ & 10 & 9 & 1 & 1 & $*$ & $*$ & 1 & 1 & $*$ & $*$ \\
\hline $1: 4: 22$ & 13 & 9 & 1 & 0 & $*$ & $*$ & 5 & 5 & $*$ & $*$ \\
\hline $1: 5: 07$ & 19 & 15 & 2 & 1 & $*$ & $*$ & 4 & 2 & $*$ & $*$ \\
\hline $1: 5: 20$ & 23 & 19 & 4 & 2 & $*$ & $*$ & 3 & 2 & $*$ & $*$ \\
\hline $1: 6: 03$ & 36 & 34 & 4 & 3 & $*$ & $*$ & 2 & 2 & $*$ & $*$ \\
\hline $1: 6: 17$ & 43 & 42 & 6 & 3 & $*$ & $*$ & 3 & 2 & $*$ & $*$ \\
\hline $1: 7: 01$ & 30 & 28 & 6 & 4 & $*$ & $*$ & 2 & 2 & $*$ & $*$ \\
\hline $1: 7: 15$ & 47 & 47 & 10 & 10 & 1 & 0 & 2 & 2 & 1 & 0 \\
\hline $1: 7: 28$ & 43 & 43 & 8 & 6 & 1 & 0 & 5 & 5 & $*$ & $*$ \\
\hline $1: 8: 12$ & 49 & 47 & 13 & 9 & 1 & 0 & 8 & 6 & 1 & 1 \\
\hline $1: 8: 27$ & 69 & 69 & 12 & 11 & 1 & 0 & 3 & 3 & 1 & 0 \\
\hline $1: 09: 09$ & 59 & 58 & 9 & 9 & 2 & 0 & 11 & 6 & $*$ & $*$ \\
\hline $2: 1: 27$ & 130 & 128 & 16 & 15 & 1 & 0 & 9 & 9 & 4 & 0 \\
\hline $2: 2: 19$ & 86 & 83 & 6 & 4 & 2 & 1 & 6 & 5 & 3 & 1 \\
\hline $2: 3: 17$ & 203 & 200 & 33 & 31 & 2 & 0 & 14 & 12 & $*$ & $*$ \\
\hline
\end{tabular}

* Sem possibilidades de produção

Percentual de produção satisfatório $=,>80 \%$

Tabela 5: Produções do sujeito de Bonilha (2005) em relação aos acentos

Ferreira-Gonçalves \& Brum de Paula (2011) voltam aos dados de Bonilha (2005) e argumentam que o padrão de acento é inicialmente rítmico, passando por modificações quando as estruturas morfológicas são adquiridas. Observe-se que esta análise não difere muito da de Santos 
(2001) - enquanto Ferreira-Gonçalves \& Brum de Paula sugerem uma reanálise na regra, Santos propõe uma modificação do domínio de aplicação da regra, que permanece a mesma. Esta diferença decorre do fato de que Ferreira-Gonçalves \& Brum de Paula assumem que a regra de acentuação se dá por criação de pés troqueus (logo, só é possível explicar os iambos iniciais se se assume que no começo do processo o pé é iambo), enquanto que Santos assume a proposta de Lee (1995), para quem a atribuição do acento lexical no português se dá por criação de um constituinte iâmbico na forma adulta. Assim, a diferença no acento entre a forma adulta e a forma infantil ocorre porque a criança cria o iambo na borda direita da palavra, enquanto o adulto o cria na borda direita do radical.

Além disso, as autoras argumentam que a emergência iâmbica encontrada nos dados de aquisição pode ser devido à frequência das palavras oxítonas na língua adulta e particularmente na fala dirigida às crianças. A Tabela 6 traz o Quadro 1 de Ferreira-Gonçalves \& Brum de Paula (2011).

\begin{tabular}{|l|l|l|l|l|l|l|}
\hline Pauta acentual & $1: 1: 22$ & $1: 3: 10$ & $1: 3: 24$ & $1: 4: 9$ & $1: 4: 22$ & $1: 5: 7$ \\
\hline Paroxítona leve & 85,7 & 72,7 & 75 & 90 & 69,2 & 78,94 \\
\hline Oxítona leve & 100 & 100 & 100 & 100 & 100 & 50 \\
\hline Oxítona & 20 & 0 & 100 & 100 & 0 & 50 \\
\hline Monossílabo leve & 100 & 100 & 100 & $*$ & $*$ & 100 \\
\hline Monossílabo pesado & $*$ & $*$ & $*$ & 0 & $*$ & 66,6 \\
\hline
\end{tabular}

Tabela 6: Realização correta (\%) de diferentes pautas acentuais pelo sujeito de Bonilha (2005) reanalisado em Ferreira-Gonçalves \& Brum de Paula (2011)

Segundo Ferreira-Gonçalves \& Brum de Paula, se se leva em conta a distribuição dos padrões na fala adulta (as autoras assumem o trabalho de Albano 2001), há uma diferença na distribuição dos padrões acentuais. No entanto, estes resultados são diferentes se se leva em conta apenas as palavras mais frequentes. As autoras então usam como comparação os resultados de Araújo et al (2011) - cf. Tabela 2 deste texto - para argumentar que "é possível estabelecer um paralelo entre a emergência de formas iâmbicas no português e a significativa frequência da pauta acentual oxítona no grupo de palavras consideradas frequentes e comuns. Salienta-se, ainda, que esse percentual pode ser ainda maior se forem considerados os itens lexicais da fala dirigida à criança" (FERREIRA-GONÇALVES \& BRUM DE PAULA, 2011, p. 58). Ora, se retomamos a Tabela 2, vemos que não temos ali a distribuição dos dados das palavras frequentes entre os diferentes padrões acentuais (o que nos permitiria saber qual dos padrões acentuais ocorre mais com as palavras frequentes). $\mathrm{O}$ que temos ali 
é que dentre todas as paroxítonas da língua, 23,1\% delas concentram-se nas palavras consideradas frequentes e $26,3 \%$ nas palavras consideradas incomuns. Dentre as palavras oxítonas do corpus, 25,6\% estão naquelas consideradas frequentes, e $21,1 \%$ entre as consideradas raras. Além do fato de que, tanto para oxítonas quanto paroxítonas, a quantidade percentual é muito próxima (e, portanto, faz-se necessária uma análise que observe se essa diferença é significativa), esses resultados absolutamente não servem para mostrar, entre as palavras frequentes, qual a distribuição de oxítonas e paroxítonas, pois a quantidade de dados destas duas categorias não é informada pelos autores. De modo a deixar clara a argumentação, façamos um exercício com os resultados de Albano - e ressaltamos que se trata apenas de um exercício, já que não temos os dados brutos de Araújo et al.. Albano (2001) encontrou 14.489 palavras paroxítonas em seu estudo, e 9488 oxítonas. Se $23,1 \%$ das palavras paroxítonas estão dentro do quartil de palavras frequentes, tem-se então 3346 palavras paroxítonas frequentes. Se 25,6\% das palavras oxítonas são frequentes, tem-se 2428 palavras oxítonas neste quartil. Se se assume que as crianças só estão considerando as palavras frequentes no processo de aquisição, elas estão ouvindo 37\% mais paroxítonos do que oxítonos (em nosso exercício, 918 paroxítonas a mais do que as oxítonas).

Para além deste problema metodológico, chama a atenção que Ferreira-Gonçalves \& Brum de Paula, para fins comparativos com Araújo et al, passam também a usar os valores percentuais, tais como apresentados na Tabela 5. No entanto, como já chamamos a atenção, há que se notar que as percentagens devem ser vistas com cuidado. $\mathrm{O}$ fato de que a criança produz $100 \%$ de oxítonas leves até 1;4 não diz muita coisa quando se observa tratar de apenas uma palavra em três das sessões.

Numa direção diferente, encontramos os resultados de Rapp (1994). A autora analisou o padrão acentual nas primeiras palavras ao discutir a elisão de sílabas fracas, trabalhando com dados produzidos por oito crianças entre $1 ; 6$ e 2;0 anos, elicitados através de nomeação de figuras. Os resultados foram somados para todas as crianças e segundo a autora apontaram para uma preferência para o acento paroxítono (51.4\%), sendo o padrão oxítono o segundo padrão de produção (38.2\%). Alguns problemas se colocam para utilizar este trabalho como evidência de uma preferência pelo padrão trocaico no processo de aquisição. $\mathrm{O}$ primeiro deles diz respeito ao fato de que são somados dados de um período de 6 meses e, como vimos nos trabalhos anteriores, para muitas crianças é 
exatamente por volta dos $1 ; 6$ que ocorre uma mudança pelo padrão preferencial. Outro problema é que Rapp selecionou palavras de 2 a 6 sílabas para análise, com acento nas três posições possíveis em português brasileiro. No entanto, muitas dessas palavras impedem a formação de um padrão acentual. Por exemplo, trissílabas proparoxítonas só podem criar um acento paroxítono quando há alguma elisão. Quando analisamos os resultados por categorias acentuais, o padrão que emerge é diferente, como se observa na Tabela 7, que reúne os resultados dos Quadros 29 a 39 de Rapp. ${ }^{4}$

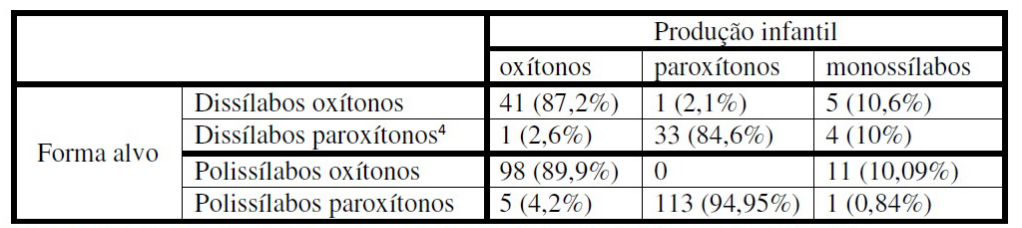

Tabela 7: distribuição dos padrões acentuais das produções dos sujeitos de Rapp (1994)

Como se pode observar, os polissílabos oxítonos nunca sofreram mudança acentual, mas transformam-se em monossílabos muito mais vezes do que os polissílabos paroxítonos. Há pouquíssima mudança acentual e a diferença percentual entre as produções é bem próxima (portanto, há que se investigar se é estatisticamente significativa).

Finalmente, exatamente por ser um trabalho experimental, não é possível analisá-lo tentando observar uma possível influência dos padrões distribucionais da fala adulta (ou da FDC).

Em suma, o que vimos acima é que a maior parte dos trabalhos aponta para uma tendência iâmbica inicial; também vimos que muitos trabalhos levantam a hipótese de esta tendência ser devida à influência da frequência de uso, mas ou apresentam problemas metodológicos que comprometem as conclusões, ou acabam por não discutir a questão.

\section{Metodologia}

Revisitamos aqui os dados analisados por Santos (2007). São dados de duas crianças - R (entre 1;3 a 2;0 anos) e L (entre 1;4 a 2;0) - e suas mães, na fala em interação com as crianças. Foram consideradas apenas as palavras (types) que ocorressem mais do que 8 vezes (tokens), pois assim torna-se possível observar as mudanças que as crianças fizessem em um mesmo alvo ao longo do período analisado. Estatisticamente, cada palavra foi considerada uma unidade amostral e o corpus avaliado para cada 
criança como uma amostra aleatória. Com isso, não pretendemos estender os resultados para toda a população de crianças (ou mães) brasileiras com a mesma faixa etária, mas podemos observar se o padrão utilizado por cada criança (ou mãe) neste corpus pode ser estendido para o universo de todas as palavras faladas por cada uma das crianças (e mães) analisadas.

As palavras alvo têm as seguintes formas adultas:

(2) a. Oxítono

b. Dissílabo Paroxítono Trissílabo Paroxítono wsw: Monossílabo ws: café, colher, comeu

sw: gato, móvel, bebe

s: $\quad$ trem, mão, dá

As palavras em (2a) são iambos e as em (2b) são troqueus. As palavras em (2c) são na forma adulta troqueus, mas estão classificadas em separado porque, a depender da sílaba átona que a criança apague, ela pode criar um iambo (se houver apagamento da postônica) ou um troqueu (se ocorrer apagamento da pretônica). Os monossílabos (cf. (2d)) também estão em destaque porque, a depender da posição que as crianças acrescentem sílabas fracas, elas podem criar iambos (se houver inserção de uma átona inicial) ou troqueus (se houver inserção de uma átona final).

No total, foram analisados 1050 dados de R. e 791 de L. Os dados foram categorizados também quanto ao tipo de palavra: palavras familiares, de léxico característico de FDC (e.g. xixi, cocô) ou palavras características de léxico da fala adulta (e.g. cavalo, menino), e da classe morfológica (verbos e não-verbos).

\section{Resultados e Discussão}

Nas duas subseções abaixo apresentamos os resultados das comparações entre a fala adulta e a FDC, de modo a observar se há diferença nestes dois registros e comparamos a distribuição dos padrões infantis com os padrões encontrados na FDC, levantando hipóteses sobre o porquê dos resultados encontrados.

\subsection{Comparando a Fala Adulta com a FDC}

Santos (2007) compara a distribuição dos padrões acentuais entre a fala adulta e a FDC. O corpus de FDC é composto da fala de duas mães, nas interações com seus filhos, também analisados pela autora. O corpus adulto 
é representado por uma reanálise dos dados de Cintra, levando em conta apenas os monossílabos tônicos, os oxítonos e os paroxítonos, padrões analisados por Santos. Os resultados encontram-se na Tabela 8, com aplicação do teste de z para duas proporções, com nível de significância de 5\%.

\begin{tabular}{|c|l|c|c|l|}
\hline criança & padrão acentual & Fala adulta (Cintra 1997) & Fala dirigida à criança & Valor_P \\
\hline \multirow{3}{*}{$\mathrm{L}$} & oxítono & $19.35 \%$ & $19.50 \%$ & 0.878 \\
\cline { 2 - 5 } & paroxítono & $67.28 \%$ & $59.28 \%$ & $<0.001$ \\
\cline { 2 - 5 } & monossílabo & $13.37 \%$ & $21.22 \%$ & $<0.001$ \\
\hline \multirow{3}{*}{$\mathrm{R}$} & oxítono & $19.35 \%$ & $23.82 \%$ & $<0.001$ \\
\cline { 2 - 5 } & paroxítono & $67.28 \%$ & $49.18 \%$ & $<0.001$ \\
\cline { 2 - 6 } & monossílabo & $13.37 \%$ & $27.00 \%$ & $<0.001$ \\
\hline
\end{tabular}

Tabela 8: resultado da comparação de padrões na fala adulta e na FDC para verbos e não verbos.

Como se pode observar, apenas para a classe dos oxítonos, na fala de uma das mães, é que não há diferença na distribuição dos padrões entre a fala adulta e a dirigida à criança. Em todos os outros casos (paroxítonos, oxítonos, monossílabos), há uma diferença na distribuição dos padrões. Especificamente, a diferença aponta uma queda na frequência de paroxítonos e um aumento na frequência de monossílabos, com as crianças. No caso da fala da mãe de R., há também uma maior frequência de oxítonos em relação à fala adulta.

Interessa-nos observar quais são os padrões mais frequentes na FDC, resumidos no Quadro 2. Nos dois casos de FDC, há uma inversão privilegiando os monossílabos e o padrão menos escutado, para as crianças, é o oxítono. Ainda assim, o padrão mais escutado é o paroxítono, como na fala adulta.

\begin{tabular}{|c|c|}
\hline Cintra 1997 & Fala dirigida a R e L \\
\hline paroxítonos > oxítonos $>$ monossílabos & Paroxítonos $>$ monossílabos > oxítonos \\
\hline
\end{tabular}

Quadro 2: Ordem de frequência de uso de padrões na fala adulta e na fala dirigida a R e L.

\subsection{Os dados infantis}

Como se pôde observar na Tabela 8, a FDC tem uma distribuição de padrões acentuais diferente da fala adulta. Essa mesma diferença é encontrada na fala das próprias crianças. A Tabela 9 mostra a quantidade de tokens monossílabos, oxítonos e paroxítonos por L. e R., tanto levando em conta as palavras familiares quanto descartando estas palavras. Considerando as palavras familiares/infantis, L. produziu 791 tokens de 64 palavras, e R. produziu 1.050 tokens de 88 palavras. Separando as palavras familiares/infantis, L. 


\begin{tabular}{|c|l|l|l|l|l|}
\hline \multicolumn{2}{|c|}{} & \multicolumn{4}{|c|}{ Padrão Acentual } \\
\cline { 3 - 6 } \multicolumn{2}{|c|}{} & iambo & troqueu & monossílabos & Total \\
\hline $\begin{array}{c}\text { Produção } \\
\text { de L }\end{array}$ & com palavras familiares & $337(42.6 \%)$ & $332(41.97 \%)$ & $122(15.42 \%)$ & 791 \\
\cline { 2 - 6 } & sem palavras familiares & $119(23 \%)$ & $331(64 \%)$ & $67(13 \%)$ & 517 \\
\hline $\begin{array}{c}\text { Produção } \\
\text { de R }\end{array}$ & com palavras familiares & $299(28.48 \%)$ & $450(42.86 \%)$ & $301(28.67 \%)$ & 1050 \\
\cline { 2 - 6 } & sem palavras familiares & $218(23.5 \%)$ & $411(44.3 \%)$ & $299(32.2 \%)$ & 928 \\
\hline
\end{tabular}

Tabela 9: distribuição dos padrões acentuais por acento e tipo de léxico para verbos e não verbos

Os resultados chamam a atenção pela diferença dos padrões de distribuição de acento pelas duas crianças. Enquanto para L as palavras familiares claramente modificam os resultados, a diferença nos resultados é bem menor para os dados de R. A ordem de frequência para as duas crianças é como no Quadro 3:

\begin{tabular}{|l|l|l|}
\hline & Com palavras familiares & Sem palavras familiares \\
\hline L & oxítonos, paroxítonos $>$ monossílabos & paroxítonos $>$ oxítonos $>$ monossílabos \\
\hline R & paroxítonos $>$ oxítonos, monossílabos & paroxítonos $>$ monossílabos $>$ oxítonos \\
\hline
\end{tabular}

Quadro 3: Ordem de frequência de uso de padrões na fala de R e L, com e sem palavras familiares.

É interessante observar que quando as palavras familiares são levadas em consideração, aumenta a quantidade de oxítonas, mas não há uma inversão na ordem e sim um equilíbrio entre os padrões. Para L, paroxítonos e oxítonos, que tinham uma distribuição bem diferente (de $64 \% \mathrm{e}$ $23 \%$, respectivamente), passam a ter a mesma frequência ( $42 \%)$. No caso de R., os oxítonos se aproximam em frequência aos monossílabos (28\%), quando antes apresentavam uma clara diferença distribucional.

Uma vez que a frequência de uso deve afetar a distribuição dos padrões, na Tabela 10 compara-se a distribuição dos padrões acentuais na FDC e na fala infantil, levando-se em conta as palavras familiares.

\begin{tabular}{|c|l|l|l|l|}
\hline criança & Padrão acentual & FDC & Produção infantil & Valor_P \\
\hline \multirow{3}{*}{$\mathrm{L}$} & iambo (ws) & $19.50 \%$ & $42.60 \%$ & $<0.001$ \\
\cline { 2 - 5 } & troqueu (sw e wsw) & $59.28 \%$ & $41.97 \%$ & $<0.001$ \\
\cline { 2 - 5 } & monossílabo (s) & $21.22 \%$ & $15.42 \%$ & $<0.001$ \\
\hline \multirow{3}{*}{$\mathrm{R}$} & iambo (ws) & $23.82 \%$ & $28.48 \%$ & 0.001 \\
\cline { 2 - 5 } & troqueu (sw e wsw) & $49.18 \%$ & $42.86 \%$ & $<0.001$ \\
\cline { 2 - 5 } & monossílabo (s) & $27 \%$ & $28.67 \%$ & 0.252 \\
\hline
\end{tabular}

Tabela 10: comparação entre o padrão acentual da FDC e a produção infantil para verbos e não verbos, com palavras familiares

Como se pode observar, exceto pelos monossílabos produzidos por R., todos os outros padrões apresentam uma diferença estatisticamente 
significante entre o que é produzido pelas crianças e o que é produzido na fala que lhes é dirigida. No caso de L., ela produz o dobro de oxítonos do que escuta e mais interessante, ela prefere os oxítonos mesmo ouvindo três vezes mais troqueus (paroxítonos). No caso de R, embora ela produza mais troqueus do que iambos, o valor_P indica que esta seleção não reflete o padrão do input. Em suma, os resultados mostram que, somando os dados de todo o período analisado, a distribuição dos padrões acentuais não reflete a distribuição dos padrões acentuais encontrados no input.

É possível levantar duas explicações para este resultado. Em primeiro lugar, pode-se imaginar que as crianças evitam, por algum motivo, algum padrão acentual específico, o que alteraria a distribuição dos padrões em sua fala. Por exemplo, segundo Kehoe (1999:32), "the absense of long words in Young children's inventories may suggest selection and avoidance (SCHWARTZ \& LEONARD 1982) or simply reflect the low frequency of multisyllabic words in the ambient language." e esta visão é partilhada por outros pesquisadores em aquisição (e.g. CLARK 2003, ELSEN 1994, FERGUSON \& FARWELL 1975, LABOV \& LABOV 1978). Uma explicação alternativa seria que, como os resultados acima somam dados de um longo período (de 1;3 a 2;0 anos), esse tipo de decisão metodológica estaria mascarando a emergência dos diferentes padrões acentuais no processo de aquisição.

Tratemos inicialmente da hipótese da evitação. Os estudos em aquisição que assumem haver esta estratégia dividem-se em dois tipos. Há os que assumem que a estratégia de evitação consiste em evitar estruturas não adquiridas utilizando no lugar estruturas como se fossem sinônimas (e.g MENN 1983, NITTROUER, STUDDERT-KENNEDY \& MCGOWAN 1989, FREITAS 1997, VELLEMAN \& VIHMAN 2006). Demuth (1995), por exemplo, argumenta que as crianças produzem as palavras iniciais como monossílabos de formato CV para evitar a questão de como se constroem pés binários. Para outros estudos, as crianças mudam as estruturas básicas de estruturas ainda não adquiridas (CLARK 2003, SCHWARTZ \& LEONARD 1982, FREITAS 1997). A inserção de vogais em ataques ramificados (transformando CCV em CVCV) é muitas vezes analisada como um processo de evitação. Freitas (1997) não usa a palavra evitação, mas discute duas estratégias que podem ser entendidas como duas acepções de evitação: seleção e reconstrução. Segundo a autora, a estratégia de seleção ocorre porque a criança não tem, em sua gramática, a estrutura que lhe permite reconhecer a estrutura do input. Por 
outro lado, a estratégia de reconstrução implica que a criança já reconheça a estrutura, mas como esta ainda não está disponível para a produção, a criança a modifica.

A Tabela 11 compara a distribuição entre a forma alvo das palavras escolhidas pelas crianças e a forma produzida, para verbos e não-verbos. Não estão incluídas aqui palavras familiares, já que, como muitas vezes implicam criações lexicais da criança, fica difícil saber se a forma produzida tem o mesmo padrão da forma alvo (tentativa).

\begin{tabular}{|c|l|l|l|l|}
\hline criança & Padrão acentual & Forma alvo da criança & Forma produzida da criança & Valor_P \\
\hline \multirow{3}{*}{ L } & iambo (ws) & $23.02 \%$ & $25.92 \%$ & 0.278 \\
\cline { 2 - 6 } & troqueu (sw e wsw) & $64.02 \%$ & $48.16 \%$ & $<0.001$ \\
\cline { 2 - 5 } & monossílabo (s) & $12.96 \%$ & $25.92 \%$ & $<0.001$ \\
\hline \multirow{3}{*}{$\mathrm{R}$} & iambo (ws) & $23.49 \%$ & $24.68 \%$ & 0.550 \\
\cline { 2 - 6 } & troqueu (sw e wsw) & $44.29 \%$ & $32.11 \%$ & $<0.001$ \\
\cline { 2 - 5 } & monossílabo (s) & $32.22 \%$ & $43.21 \%$ & $<0.001$ \\
\hline
\end{tabular}

Tabela 11: comparação entre a forma alvo do léxico selecionado pela criança e a forma efetivamente produzida para verbos e não-verbos, sem palavras familiares

A coluna 'forma alvo' traz indicações se a criança está tentando produzir palavras que tenham um determinado padrão acentual, ou se está evitando escolher palavras com este padrão. Como se pode perceber, no léxico de L. 64\% das palavras são troqueus na forma adulta, e no caso de R. são 44\%. Logo, a hipótese de que as crianças estão produzindo mais iambos porque a seleção lexical privilegia iambos não se sustenta.

A coluna 'forma produzida' traz informações sobre o que as crianças fizeram com as formas prosódicas das palavras alvo e o resultado do valor_P indica se há ou não uma relação entre a forma selecionada e a forma efetivamente produzida. Como se pode observar, a produção efetiva de iambos por L. e R. é muito próxima da seleção dos itens lexicais, o que significa que a maior parte das palavras com outros padrões acentuais não foram produzidas como iambos. O que se percebe é um aumento nas formas monossilábicas (e.g., L. produziu 25.92\% de monossílabos, mas as palavras por ela selecionadas com este padrão eram apenas $12.96 \%$ ). E mesmo com muitos dos troqueus sendo transformados em monossílabos, eles ainda são produzidos corretamente em grande quantidade e, mais importante, em quantidade maior ou quase equivalente aos monossílabos.

A Tabela 12 traz o mesmo tipo de análise, mas considerando apenas não-verbos, já que os verbos apresentam um padrão acentual que é influenciado pela morfologia e que pode estar mais cristalizado por estar associado também a questões semânticas (como o tempo/modo) das sen- 
tenças proferidas (isto é, diferentemente dos não-verbos, a seleção de um sinônimo raramente afeta a posição do acento em verbos. E.g.: bebia vs. tomava). Pelas mesmas razões acima, as palavras familiares foram desconsideradas no cálculo.

\begin{tabular}{|c|l|l|l|l|}
\hline criança & Padrão acentual & Forma alvo da criança & Forma produzida da criança & Valor_P \\
\hline \multirow{3}{*}{$\mathrm{L}$} & iambo (ws) & $5.53 \%$ & $11.06 \%$ & 0.029 \\
\cline { 2 - 5 } & troqueu (sw e wsw) & $94.47 \%$ & $68.09 \%$ & $<0.001$ \\
\cline { 2 - 5 } & monossílabo (s) & $0 \%$ & $20.85 \%$ & $<0.001$ \\
\hline \multirow{3}{*}{$\mathrm{R}$} & iambo (ws) & $3.35 \%$ & $15.48 \%$ & $<0.001$ \\
\cline { 2 - 5 } & troqueu (sw e wsw) & $82.43 \%$ & $63.18 \%$ & $<0.001$ \\
\cline { 2 - 5 } & monossílabo (s) & $14.23 \%$ & $21.34 \%$ & 0.041 \\
\hline
\end{tabular}

Tabela 12: comparação entre a forma alvo do léxico selecionado pela criança e a forma efetivamente produzida para não-verbos, sem palavras familiares

Como se pode observar, o padrão iâmbico na forma alvo e na efetivamente produzida pelas crianças para não-verbos ainda é o menos produtivo. Percebe-se também que os paroxítonos se transformam em iambos e em monossílabos. Interessantemente L. não seleciona nenhum nome monossílabo, mas acaba por realizar $20 \%$ de sua produção com este padrão.

Nos dois casos, tem-se que a distribuição dos padrões é paroxítonos $>$ monossílabos $>$ oxítonos. Trata-se exatamente do padrão encontrado na FDC (Cf. Quadro 2), mas com uma crucial diferença: na FDC estão computadas as palavras infantis. Como vimos na Tabela 9, quando se leva em conta as palavras familiares, a distribuição dos padrões das crianças não reflete a distribuição dos padrões a que ela está exposta. Nas Tabelas 10,11 e 12 é possível observar que as crianças nem evitam certos padrões por seleção, nem por estratégias de reparo. Assim, pode-se concluir que a distribuição dos padrões não é devida à evitação de padrões.

A alternativa levantada acima é de que os resultados são devidos a um problema metodológico. Especificamente, os resultados agrupam um período de análise muito longo e que, se for observado com mais detalhe, diferenças na distribuição dos padrões poderão emergir.

As Tabelas 13-16 trazem a produção por frequência de tokens de não-verbos e sem as palavras familiares, pelas razões já mencionadas para a Tabela 11. As segunda, terceira, quarta e quinta colunas indicam a produção da criança. A percentagem é apresentada ao lado dos dados brutos, mas não fazemos comentários a partir delas porque são poucos dados e usar percentagens pode nos levar a equívocos de interpretação (por exemplo, observe que na Tabela 13, aos 1;6 L. tem 100\% de produção trocaica, 
percentual muito próximo de 2;0. Só que nesta última faixa etária são 26 tokens, enquanto que aos 1;6 são apenas 6).

A Tabela 13 traz a produção de palavras com forma alvo sw, um troqueu. Como se pode observar, desde o início há mais produções corretas do que modificadas deste tipo de padrão (apenas aos 1;5 há mais sw sendo produzidos como ws, mas veja-se que são poucos tokens). Quando modificadas, elas sempre tendem a se tornar monossílabas.

\begin{tabular}{|c|c|c|c|c|c|c|c|c|c|c|}
\hline \multirow[b]{2}{*}{ Idade } & \multicolumn{5}{|c|}{ Produção de nomes sw por L. } & \multicolumn{5}{|c|}{ Produção de nomes sw por R. } \\
\hline & $\overline{\text { SW }}$ & ws & $\bar{s}$ & wsw & total & $\mathrm{SW}$ & ws & $\bar{s}$ & WSW & total \\
\hline $1 ; 03$ & - & - & - & - & - & 0 & 0 & 0 & 0 & 0 \\
\hline $1 ; 04$ & $\begin{array}{c}21 \\
(63.6 \%)\end{array}$ & $\begin{array}{c}3 \\
(9.1 \%)\end{array}$ & $\begin{array}{c}9 \\
(27.3 \%)\end{array}$ & 0 & $\begin{array}{c}33 \\
(100 \%)\end{array}$ & 0 & 0 & 0 & 0 & 0 \\
\hline $1 ; 05$ & $\begin{array}{c}2 \\
(20 \%)\end{array}$ & 0 & $\begin{array}{c}8 \\
(80 \%)\end{array}$ & 0 & $\begin{array}{c}10 \\
(100 \%)\end{array}$ & $\begin{array}{c}2 \\
(28.6 \%)\end{array}$ & $\begin{array}{c}1 \\
(14.3 \%)\end{array}$ & $\begin{array}{c}4 \\
(57.1 \%)\end{array}$ & 0 & $\begin{array}{c}7 \\
(100 \%)\end{array}$ \\
\hline $1 ; 06$ & $\begin{array}{c}6 \\
(100 \%)\end{array}$ & 0 & 0 & 0 & $\begin{array}{c}6 \\
(100 \%)\end{array}$ & $\begin{array}{c}19 \\
(70.4 \%)\end{array}$ & \begin{tabular}{|c|}
1 \\
$(3.7 \%)$ \\
\end{tabular} & $\begin{array}{c}7 \\
(25.92 \%)\end{array}$ & 0 & $\begin{array}{c}27 \\
(100 \%)\end{array}$ \\
\hline $1 ; 07$ & $\begin{array}{c}6 \\
(66.7 \%)\end{array}$ & 0 & \begin{tabular}{c|}
3 \\
$(33.3 \%)$ \\
\end{tabular} & 0 & $\begin{array}{c}9 \\
(100 \%)\end{array}$ & $\begin{array}{c}11 \\
(84.6 \%)\end{array}$ & 0 & $\begin{array}{c}2 \\
(15.4 \%)\end{array}$ & 0 & $\begin{array}{c}13 \\
(100 \%)\end{array}$ \\
\hline $1 ; 08$ & $\begin{array}{c}28 \\
(90.3 \%)\end{array}$ & $\begin{array}{c}2 \\
(6.5 \%)\end{array}$ & $\begin{array}{c}1 \\
(3.2 \%)\end{array}$ & 0 & $\begin{array}{c}31 \\
(100 \%)\end{array}$ & $\begin{array}{c}30 \\
(93.7 \%) \\
\end{array}$ & 0 & $2(6.5 \%)$ & 0 & $\begin{array}{c}32 \\
(100 \%)\end{array}$ \\
\hline $1 ; 09$ & $\begin{array}{c}23 \\
(63.9 \%) \\
\end{array}$ & 0 & \begin{tabular}{|c|}
13 \\
$(36.1 \%)$ \\
\end{tabular} & 0 & $\begin{array}{c}36 \\
(100 \%) \\
\end{array}$ & $\begin{array}{c}2 \\
(100 \%)\end{array}$ & 0 & 0 & 0 & $\begin{array}{c}2 \\
(100 \%)\end{array}$ \\
\hline $1 ; 10$ & $\begin{array}{c}1 \\
(100 \%)\end{array}$ & 0 & 0 & 0 & $\begin{array}{c}1 \\
(100 \%)\end{array}$ & 0 & 0 & 0 & 0 & 0 \\
\hline $1 ; 11$ & $\begin{array}{c}8 \\
(53.3)\end{array}$ & $\begin{array}{c}4 \\
(26.7 \%)\end{array}$ & $\begin{array}{c}3 \\
(20 \%)\end{array}$ & 0 & $\begin{array}{c}15 \\
(100 \%)\end{array}$ & $\begin{array}{c}2 \\
(100 \%)\end{array}$ & 0 & 0 & 0 & $\begin{array}{c}2 \\
(100 \%)\end{array}$ \\
\hline $2 ; 0$ & $\begin{array}{c}26 \\
(96.3 \%)\end{array}$ & 0 & $\begin{array}{c}1 \\
(3.7 \%)\end{array}$ & 0 & $\begin{array}{c}27 \\
(100 \%)\end{array}$ & $\begin{array}{c}9 \\
(90 \%)\end{array}$ & 0 & $\begin{array}{c}1 \\
(10 \%)\end{array}$ & 0 & $\begin{array}{c}10 \\
(100 \%)\end{array}$ \\
\hline Total & 121 & 9 & 38 & 0 & 168 & 75 & 2 & 16 & 0 & 93 \\
\hline
\end{tabular}

Tabela 13: produção de palavras alvo sw por R e L, não-verbos, sem palavras familiares, para cada sessão analisada

A Tabela 14 traz os nomes com padrão ws. Como se pode perceber, são bem menos itens lexicais ws que as crianças tentam produzir. Elas tanto produzem corretamente quanto truncam, mas nunca mudam o acento ou acrescentam uma sílaba fraca (transformando-o em wsw). 


\begin{tabular}{|c|c|c|c|c|c|c|c|c|c|c|}
\hline \multirow{2}{*}{ Idade } & \multicolumn{9}{|c|}{ Produç̃̃o de nomes ws por L. } & \multicolumn{5}{c|}{ Produção de nomes ws por R. } \\
\cline { 2 - 12 } & sw & ws & s & wsw & total & sw & ws & s & wsw & Total \\
\hline $1 ; 03$ & - & - & - & - & - & 0 & 0 & 0 & 0 & 0 \\
\hline $1 ; 04$ & 0 & 0 & 0 & 0 & 0 & 0 & 0 & 0 & 0 & 0 \\
\hline $1 ; 05$ & 0 & 0 & $1(100 \%)$ & 0 & $1(100 \%)$ & 0 & 0 & 0 & 0 & 0 \\
\hline $1 ; 06$ & 0 & 0 & $1(100 \%)$ & 0 & $1(100 \%)$ & 0 & $1(100 \%)$ & 0 & 0 & $1(100 \%)$ \\
\hline $1 ; 07$ & 0 & 0 & 0 & 0 & 0 & 0 & $4(100 \%)$ & 0 & 0 & $4(100 \%)$ \\
\hline $1 ; 08$ & 0 & $2(100 \%)$ & 0 & 0 & $2(100 \%)$ & 0 & $3(100 \%)$ & 0 & 0 & $3(100 \%)$ \\
\hline $1 ; 09$ & 0 & $1(50 \%)$ & $1(50 \%)$ & 0 & $2(100 \%)$ & 0 & 0 & 0 & 0 & 0 \\
\hline $1 ; 10$ & 0 & 0 & 0 & 0 & 0 & 0 & 0 & 0 & 0 & 0 \\
\hline $1 ; 11$ & 0 & $2(50 \%)$ & $2(50 \%)$ & 0 & $4(100 \%)$ & 0 & 0 & 0 & 0 & 0 \\
\hline $2 ; 0$ & 0 & $3(100 \%)$ & 0 & 0 & $3(100 \%)$ & 0 & 0 & 0 & 0 & 0 \\
\hline Total & 0 & 8 & 5 & 0 & 13 & 0 & 8 & 0 & 0 & 8 \\
\hline
\end{tabular}

Tabela 14: produção de palavras alvo ws por R e L, não verbos, sem palavras familiares, para cada sessão analisada

A Tabela 15 traz em separado os nomes com padrão paroxítono wsw. Isto porque eles podem ser facilmente transformados em iambos ou troqueus com apenas o apagamento de uma sílaba. Pode-se observar que até $1 ; 7 \mathrm{~L}$. ou os trunca para ws ou para monossílabos. É somente a partir de $1 ; 8$ que a criança passa a truncá-los para sw. $\mathrm{R}$ já produz este padrão bem cedo e até $1 ; 6$ os truncamentos favorecem também a forma iâmbica.

\begin{tabular}{|c|c|c|c|c|c|c|c|c|c|c|}
\hline \multirow[b]{2}{*}{ Idade } & \multicolumn{5}{|c|}{ Produção de nomes wsw por L. } & \multicolumn{5}{|c|}{ Produção de nomes wsw por R. } \\
\hline & Sw & ws & $\mathrm{s}$ & WSW & total & SW & ws & $\mathrm{s}$ & wsw & Total \\
\hline $1 ; 03$ & - & - & - & - & - & $\begin{array}{c}1 \\
(10 \%)\end{array}$ & $\begin{array}{c}9 \\
(90 \%) \\
\end{array}$ & 0 & 0 & $\begin{array}{c}10 \\
(100 \%)\end{array}$ \\
\hline $1 ; 04$ & 0 & 0 & $\begin{array}{c}1 \\
(100 \%)\end{array}$ & 0 & $\begin{array}{c}1 \\
(100 \%)\end{array}$ & 0 & $\begin{array}{c}2 \\
(100 \%)\end{array}$ & 0 & 0 & $\begin{array}{c}2 \\
(100 \%)\end{array}$ \\
\hline $1 ; 05$ & 0 & $\begin{array}{c}4 \\
(80 \%) \\
\end{array}$ & $\begin{array}{c}1 \\
(20 \%)\end{array}$ & 0 & $\begin{array}{c}5 \\
(100 \%)\end{array}$ & 0 & 0 & 0 & $\begin{array}{c}1 \\
(100 \%)\end{array}$ & $\begin{array}{c}1 \\
(100 \%)\end{array}$ \\
\hline $1 ; 06$ & 0 & 0 & 0 & 0 & 0 & $\begin{array}{c}14 \\
(29.8 \%)\end{array}$ & $\begin{array}{c}7 \\
(14.9 \%)\end{array}$ & $\begin{array}{c}7 \\
(14.9 \%) \\
\end{array}$ & $\begin{array}{c}19 \\
(40.4 \%)\end{array}$ & $\begin{array}{c}47 \\
(100 \%)\end{array}$ \\
\hline $1 ; 07$ & 0 & 0 & $\begin{array}{c}1 \\
(100 \%)\end{array}$ & 0 & $\begin{array}{c}1 \\
(100 \%)\end{array}$ & $\begin{array}{c}1 \\
(25 \%)\end{array}$ & 0 & 0 & $\begin{array}{c}3 \\
(75 \%)\end{array}$ & $\begin{array}{c}4 \\
(100 \%)\end{array}$ \\
\hline $1 ; 08$ & $\begin{array}{c}1 \\
(16.7 \%)\end{array}$ & $\begin{array}{c}4 \\
(66.7 \%)\end{array}$ & $\begin{array}{c}1 \\
(16.7 \%)\end{array}$ & 0 & $\begin{array}{c}6 \\
(100 \%)\end{array}$ & 0 & 0 & 0 & $\begin{array}{c}16 \\
(100 \%)\end{array}$ & $\begin{array}{c}16 \\
(100 \%)\end{array}$ \\
\hline $1 ; 09$ & \begin{tabular}{c|}
7 \\
$(58.3 \%)$ \\
\end{tabular} & 0 & $\begin{array}{c}2 \\
(16.7 \%)\end{array}$ & $\begin{array}{c}3 \\
(25 \%)\end{array}$ & $\begin{array}{c}12 \\
(100 \%)\end{array}$ & 0 & $\begin{array}{c}2 \\
(50 \%) \\
\end{array}$ & 0 & $\begin{array}{c}2 \\
(50 \%)\end{array}$ & $\begin{array}{c}4 \\
(100 \%)\end{array}$ \\
\hline $1 ; 10$ & 0 & 0 & 0 & $\begin{array}{c}2 \\
(100 \%)\end{array}$ & $\begin{array}{c}2 \\
(100 \%)\end{array}$ & 0 & 0 & 0 & $\begin{array}{c}1 \\
(100 \%)\end{array}$ & $\begin{array}{c}1 \\
(100 \%)\end{array}$ \\
\hline $1 ; 11$ & 0 & 0 & 0 & $\begin{array}{c}9 \\
(100 \%)\end{array}$ & $\begin{array}{c}9 \\
(100 \%)\end{array}$ & 0 & 0 & 0 & $\begin{array}{c}8 \\
(100 \%)\end{array}$ & $\begin{array}{c}8 \\
(100 \%)\end{array}$ \\
\hline $2 ; 0$ & $\begin{array}{c}3 \\
(16.7 \%) \\
\end{array}$ & $\begin{array}{c}1 \\
(5.5 \%) \\
\end{array}$ & 0 & $\begin{array}{c}14 \\
(77.8 \%) \\
\end{array}$ & $\begin{array}{c}18 \\
(100 \%) \\
\end{array}$ & 0 & $\begin{array}{c}1 \\
(9.1 \%)\end{array}$ & 0 & $\begin{array}{c}10 \\
(90.9 \%)\end{array}$ & $\begin{array}{c}11 \\
(100 \%)\end{array}$ \\
\hline Total & 11 & 9 & 6 & 28 & 54 & 16 & 21 & 7 & 60 & 104 \\
\hline
\end{tabular}

Tabela 15: produção de palavras alvo wsw por R e L, não verbos, sem palavras familiares, para cada sessão analisada 
Em suma, o que se percebe nas Tabelas 13 a 15 é que há a produção de muitos troqueus (o que já havia sido detectado nas Tabelas que mostram que as crianças não evitam estas formas), mas que a tendência de truncamento favorece os iambos no período inicial analisado. Até 1;6, há mais mudanças para iambos do que para troqueus.

Finalmente, observemos o que ocorre com as palavras monossilábicas na Tabela 16. Como vimos na Tabela 6, L. não seleciona este tipo de palavra (embora produza palavras polissilábicas truncadas para monossílabos). Para a criança R., podemos observar que eles são produzidos ou corretamente, ou transformados em iambos, até 1;7, o mesmo período em que wsw são produzidos como iambos.

\begin{tabular}{|l|c|c|c|c|c|}
\hline \multirow{2}{*}{ Idade } & \multicolumn{5}{|c|}{ Producão de nomes s por R. } \\
\cline { 2 - 6 } & Sw & ws & S & wsw & total \\
\hline $1 ; 03$ & 0 & 0 & 0 & 0 & 0 \\
\hline $1 ; 04$ & 0 & 0 & $6(100 \%)$ & 0 & $6(100 \%)$ \\
\hline $1 ; 05$ & 0 & $2(40 \%)$ & $3(60 \%)$ & 0 & $5(100 \%)$ \\
\hline $1 ; 06$ & 0 & 0 & $5(100 \%)$ & 0 & $5(100 \%)$ \\
\hline $1 ; 07$ & 0 & $4(33.3 \%)$ & $8(66.7 \%)$ & 0 & $12(100 \%)$ \\
\hline $1 ; 08$ & 0 & 0 & $1(100 \%)$ & 0 & $1(100 \%)$ \\
\hline $1 ; 09$ & 0 & 0 & 0 & 0 & 0 \\
\hline $1 ; 10$ & 0 & 0 & $1(100 \%)$ & 0 & $1(100 \%)$ \\
\hline $1 ; 11$ & 0 & 0 & 0 & 0 & 0 \\
\hline $2 ; 0$ & 0 & 0 & $4(100 \%)$ & 0 & $4(100 \%)$ \\
\hline Total & 0 & 6 & 28 & 0 & 34 \\
\hline
\end{tabular}

Tabela 16: produção de palavras alvo s por R, não verbos, sem palavras familiares, para cada sessão analisada

Em resumo, o que se percebe das Tabelas 13-16 é que nos primeiros meses analisados $(1 ; 3-1 ; 5)$, há uma tendência para a modificação para o padrão iâmbico. A partir de 1;6, aparecem mais modificações para o padrão trocaico - especialmente quando se leva em conta a forma wsw. Interessantemente, padrões sw são modificados para ws, mas padrões ws e s nunca são modificados para sw, que é o padrão acentual mais frequente da língua.

Vejamos agora o que ocorre com as palavras familiares. As Tabelas 17-18 somam os resultados das duas crianças, já que são poucos dados. Não houve palavras alvo wsw deste tipo.

Como se observa na Tabela 17, tem-se 38 palavras com padrão sw versus 253 palavras com padrão ws. Esse fato aponta que estas palavras do léxico infantil são predominantemente contra o padrão acentual das palavras mais frequentes no léxico adulto. Se uma primeira hipótese é 
que a criança começa adquirindo o que é mais frequente, uma hipótese correlata é que suas criações - ou o léxico que lhe é dirigido - deveria reforçar este padrão mais frequente. No entanto, vimos que não é o que ocorre nem na fala que lhe é dirigida (cf Tabela 10), nem no uso que ela faz deste tipo de palavra.

\begin{tabular}{|c|c|c|c|c|c|c|c|c|c|c|}
\hline \multirow{2}{*}{ Idade } & \multicolumn{4}{|c|}{ Producão de nomes sw por R e } & \multicolumn{4}{c|}{ Producão de nomes ws por R e L } \\
\cline { 2 - 11 } & sw & ws & s & wsw & total & sw & ws & s & wsw & Total \\
\hline $1 ; 03$ & $\begin{array}{c}5 \\
(55.6 \%)\end{array}$ & 0 & $\begin{array}{c}4 \\
(44.4 \%)\end{array}$ & 0 & $\begin{array}{c}9 \\
(100 \%\end{array}$ & 0 & $3(100 \%)$ & 0 & 0 & $3(100 \%)$ \\
\hline $1 ; 04$ & 0 & 0 & 0 & 0 & 0 & 1 & 38 & 2 & 0 & $\begin{array}{c}41 \\
(100 \%)\end{array}$ \\
\hline $1 ; 05$ & $\begin{array}{c}7 \\
(70 \%)\end{array}$ & $\begin{array}{c}1 \\
(10 \%)\end{array}$ & $\begin{array}{c}2 \\
(20 \%)\end{array}$ & 0 & $\begin{array}{c}10 \\
(100 \%\end{array}$ & 0 & $\begin{array}{c}29 \\
(100 \%)\end{array}$ & 0 & 0 & $\begin{array}{c}29 \\
(100 \%)\end{array}$ \\
\hline $1 ; 06$ & $\begin{array}{c}17 \\
(94.44 \%)\end{array}$ & $\begin{array}{c}1 \\
(5.6 \%)\end{array}$ & 0 & 0 & $\begin{array}{c}18 \\
(100 \%\end{array}$ & $\begin{array}{c}3 \\
(7.3 \%)\end{array}$ & $\begin{array}{c}38 \\
(92.7 \%)\end{array}$ & 0 & 0 & $\begin{array}{c}41 \\
(100 \%)\end{array}$ \\
\hline $1 ; 07$ & 0 & 0 & 0 & 0 & 0 & $\begin{array}{c}2 \\
(9.1 \%)\end{array}$ & $\begin{array}{c}20 \\
(90.9 \%)\end{array}$ & 0 & 0 & $\begin{array}{c}22 \\
(100 \%)\end{array}$ \\
\hline $1 ; 08$ & 0 & 0 & 0 & 0 & 0 & 0 & $\begin{array}{c}28 \\
(100 \%)\end{array}$ & 0 & 0 & $\begin{array}{c}28 \% \\
(100 \%)\end{array}$ \\
\hline $1 ; 09$ & 0 & 0 & 0 & 0 & 0 & $\begin{array}{c}2 \\
(7.4 \%)\end{array}$ & $\begin{array}{c}25 \\
(92.6 \%)\end{array}$ & 0 & 0 & $\begin{array}{c}27 \\
(100 \%)\end{array}$ \\
\hline $1 ; 10$ & 0 & 0 & 0 & 0 & 0 & 0 & $3(100 \%)$ & 0 & 0 & $\begin{array}{c}3 \\
(100 \%)\end{array}$ \\
\hline $1 ; 11$ & 1 & 0 & 0 & 0 & $\begin{array}{c}1 \\
(100 \%\end{array}$ & 0 & $\begin{array}{c}14 \\
(93.3 \%)\end{array}$ & $\begin{array}{c}1 \\
(6.7 \%)\end{array}$ & 0 & $\begin{array}{c}15 \\
(100 \%)\end{array}$ \\
\hline $2 ; 0$ & $\begin{array}{c}1 \\
(100 \%)\end{array}$ & 0 & 0 & 0 & $\begin{array}{c}1 \\
(100 \%\end{array}$ & 0 & $\begin{array}{c}42 \\
(95.4 \%)\end{array}$ & $\begin{array}{c}1 \\
(2.3 \%)\end{array}$ & $\begin{array}{c}1 \\
(2.3 \%)\end{array}$ & $\begin{array}{c}44 \\
(100 \%)\end{array}$ \\
\hline Total & 30 & 2 & 6 & 0 & 38 & 8 & 240 & 4 & 1 & 253 \\
\hline
\end{tabular}

Tabela 17: produção de palavras alvo familiares não verbos sw e ws por Re L, para cada sessão analisada

A Tabela 18 traz as palavras familiares de padrão monossilábico. Como se pode observar, houve apenas um caso de epêntese, que criou uma forma iâmbica.

\begin{tabular}{|l|c|c|c|c|c|}
\hline \multirow{2}{*}{ Idade } & \multicolumn{5}{|c|}{ Produção de nomes s por R e L } \\
\cline { 2 - 6 } & SW & ws & S & wsw & total \\
\hline $1 ; 03$ & 0 & 0 & 0 & 0 & 0 \\
\hline $1 ; 04$ & 0 & 0 & $5(100 \%)$ & 0 & $5(100 \%)$ \\
\hline $1 ; 05$ & 0 & $1(12.5 \%)$ & $7(87.5 \%)$ & 0 & $8(100 \%)$ \\
\hline $1 ; 06$ & 0 & 0 & $4(100 \%)$ & 0 & $4(100 \%)$ \\
\hline $1 ; 07$ & 0 & 0 & $2(100 \%)$ & 0 & $2(100 \%)$ \\
\hline $1 ; 08$ & 0 & 0 & $1(100 \%)$ & 0 & $1(100 \%)$ \\
\hline $1 ; 09$ & 0 & 0 & $4(100 \%)$ & 0 & $4(100 \%)$ \\
\hline $1 ; 10$ & 0 & 0 & $3(100 \%)$ & 0 & $3(100 \%)$ \\
\hline $1 ; 11$ & 0 & 0 & $9(100 \%)$ & 0 & $9(100 \%)$ \\
\hline $2 ; 0$ & 0 & 0 & $22(100 \%)$ & 0 & $22(100 \%)$ \\
\hline Total & 0 & 1 & 57 & 0 & 58 \\
\hline
\end{tabular}

Tabela 18: produção de palavras alvo familiares não verbos s por R e L, para cada sessão analisada 
Os resultados distribuídos ao longo do período analisado não nos permitem fazer análises estatísticas já que acabam por ser, por vezes, de quantidade muito baixa. Neste caso, como em todos os trabalhos apresentados na seção 2 , temos casos de sessões com 1 ou 2 produções. No entanto, foi possível observar que ao compararmos a FDC com a sua própria fala somando todo o período, percebe-se que não é a FDC que dirige a produção infantil ao padrão iâmbico - quer no léxico adulto, quer nas palavras pertencentes ao léxico familiar/infantil. Nota-se que, embora ainda haja a produção de mais paroxítonos, as mudanças de acento por parte das crianças dirigem-se mais ao padrão iâmbico do que ao padrão trocaico. Ora, se mesmo ao somarmos todos os dados não é possível encontrar uma correlação entre a fala infantil e a fala que lhe é dirigida, quanto mais seria o caso se fosse possível analisar estatisticamente apenas o período inicial, quando há ainda mais produções iâmbicas (enquanto que há mais produções trocaicas na fala adulta). Troqueus sw transformam-se em iambos, enquanto que iambos e monossílabos nunca são modificados para o padrão trocaico. Troqueus wsw inicialmente transformam-se em ws, somente mais tarde aparecem também como sw - no mesmo momento em que já aparecem produzidos corretamente. Assim, a conclusão a que chegamos só pode ser que a distribuição dos padrões acentuais infantis não espelha a distribuição dos padrões acentuais do input, ou em outras palavras, que a frequência de uso dos padrões acentuais não influencia a emergência dos padrões acentuais infantis.

\section{Considerações Finais}

Atualmente muitos trabalhos advogam que a frequência dos padrões na língua alvo afeta o processo de aquisição da linguagem. Neste artigo, investigamos esta questão olhando para a aquisição dos padrões prosódicos das palavras - especificamente, a posição do acento. O português brasileiro é uma língua interessante para esta análise já que todas as descrições sobre a fala adulta apontam para uma predominância de acento paroxítono, enquanto que - exceto por um experimento - todos os trabalhos reportados que trazem dados quantitativos sobre o padrão acentual infantil apontam para uma prevalência do acento final (iambo) no início do processo de aquisição. Este artigo revisita os resultados de estudos anteriores e a análise de Santos (2007) sobre a influência do input, especificamente da FDC, para dois sujeitos, buscando, estatisticamente, por relações significativas entre a fala infantil e a que lhe é dirigida. Os 
resultados apontaram que não há uma correlação entre a distribuição das estruturas prosódicas infantis e da fala que lhe é dirigida. A hipótese de que esta influência da frequência é afetada porque a criança aplica uma estratégia de evitação de algum padrão foi então testada e os resultados também foram negativos. Não é possível encontrar nenhuma evidência de que a criança evita algum padrão acentual.

Em suma, os resultados encontrados não permitem chegar à conclusão de que a emergência dos padrões acentuais é afetada pela distribuição da frequência dos padrões na fala do input.

\section{PROSODIC PATTERNS AND INPUT IN LANGUAGE ACQUISITION}

\section{ABSTRACT}

The majority of studies dealing with the prosodic template of first words in the past decades found a trochaic (strong-weak) tendency across languages. One line of explanation for this tendency is that trochees result from a left default value for the parameter nucleus of the foot (e.g. DRESHER 1992, FIKKERT 1994). However, as most of these studies discussed languages that are trochaic in adult form (e.g. English, Dutch), it is difficult to tease apart if the early trochees are due to this default value or if they just reflect the pattern of the target language. Furthermore, some studies have shown that is not the case that children always present a trochaic tendency (e.g. DEMUTH 1996). In this regard, Brazilian Portuguese (BP) becomes a very interesting language to analyze. On the one hand, it has more trochees than iambs (weak-strong) in adult speech. On the other hand, children begin producing more iambs than trochees (e.g. SANTOS 2001, 2007, BONILHA 2005, BAIA 2008). One could claim that this unexpected iambic tendency in early BP is consistent with the frequency of multisyllabic words in the ambient language (e.g. KEHOE 1999, ROARK \& DEMUTH 2000, PRIETO 2006). In this paper we put this alternative explanation to test, by analyzing data from 2 BP speaking children (from 
$1 ; 3$ to $3 ; 6$ years old) and their caretakers. If this child directed speech (FDC) approach is correct, we should expect to find more iambs than trochees in FDC, given that previous analyses of BP speaking children's data found an iambic tendency. The results show that FDC actually has a different distributional pattern than adult language, but trochees still outnumber iambs. Furthermore, children's production has a different pattern than CDS. Therefore, FDC cannot explain the early prosodic patterns of BP either. Additionally, the results showed that children are not avoiding any specific prosodic pattern in their selection. Moreover, it is also not the case that children avoid some patterns in their production. In conclusion, our results clearly discard the hypotheses that children's initial prosodic patterns reflect FDC's distributional patterns. KEY-WORDS: acquisition of word stress patterns, input, frequency of use

NOTAS

${ }^{1}$ Neste artigo, utilizamos s para marcar a sílaba forte e w para a sílaba fraca.

2 E.g. Berman (1977), Dresher (1992), Fikkert (1994), Adam \& Bat-El (2008), mas Rose \& Champdoizeau (2008).

${ }^{3}$ M. produz 2 palavras proparoxítonas. Na Tabela 4, uma aos 1;6 (1\%) e outra aos $2 ; 0(0,5 \%)$.

${ }^{4}$ Houve uma produção proparoxítona (2,6\%). 


\section{REFERÊNCIAS}

ALBANO, E. C. O gesto e suas bordas: esboço de fonologia acústico-articulatória do português Brasileiro Campinas: Mercado de Letras. 2001

ADAM, G.; BAT-EL, O. The trochaic bias is universal: new evidence from Hebrew. . In: A. GAVARRÓ \& M. J. FREITAS. Language Acquisition and Development: Proceedings of GALA 2007. Cambridge Scholars Pub. 2008. pp.12-24. ARAÚJO, G.; GUIMARÃES-FILHO, Z.; OLIVEIRA, L. \& M. VIARO. As proparoxítonas e o sistema acentual do português. In: G. A. ARAÚJO, ed., O Acento em Português: abordagens fonológicas Parábola editorial, São Paulo 2007 pp. 37-60.

BAIA, M. F. O modelo prosódico inicial do português brasileiro: uma questão metodológica? Dissertação de mestrado. São Paulo: Universidade de São Paulo. 2008.

BAIA, M. F. A reduplicação fonológica na aquisição do português brasileiro: uma comparação com outras línguas românicas. ReVEL, v. 8, n. 15, pp. 31-46. 2010 BAIA, M. F. Os templates no desenvolvimento fonológico: o caso do português brasileiro. Tese de Doutorado. SP: Universidade de São Paulo. 2013 .

BENEVIDES, A. O acento primário em pseudopalavras: uma abordagem experimental. Dissertação de Mestrado. SP: Universidade de São Paulo. 2016.

BERMAN, R. A. Natural phonological processes at the one-word stage. Língua 43:1-21, 1977.

BISOL, L. O acento e o pé métrico binário. Cadernos de Estudos Linguísticos 22:69-80. 1992.

BONILHA, G. F. G. Aquisição Fonológica do Português Brasileiro: uma abordagem conexionista da teoria da otimidade. Tese de doutorado, Porto Alegre: Pontifícia Universidade Católica do Rio Grande do Sul. 2005.

BYBEE, J. \& HOPPER, P. Frequency effects and the emergence of linguistic structure. Amsterdam: John Benjamins, 2001. 494 p.

CANTONI, M. M. O Acento no Português Brasileiro: uma abordagem experimental. Tese de Doutorado. Belo Horizonte: Universidade Federal de Minas Gerais. 2013.

CINTRA, G. Distribuição de padrões acentuais no vocábulo em português. Confluência 5(3): 83-92 ed. Unesp, Assis. 1997.

CLARK, E. First Language Acquisition Cambridge University Press. 2003. 
DEMUTH, K. The prosodic structure of early words. In: J. MORGAN \& K. DEMUTH, eds., Signal to Syntax: Bootstrapping from Speech to Grammar in Early Acquisition Hillsdale: Lawrence Erlbaum Associates. 1996 pp. 171-184.

DRESHER, E. B. A learning model for a parametric theory in phonology. In: R. LEVINE, ed., Formal Grammar: Theory and Implementation. Oxford University Press, 1992 pp. 290-317.

ELSEN, H. Phonological constraints and overextensions. First Language 14:305-315. 1994.

FERGUSON, C. A. \& C. B. FARWELL Words and Sounds in early language acquisition. Language 51:419-439. 1975.

FERGUSON, C. Talking to children: A search for universals. In J.H. GREENBERG, C.A. FERGUSON \& E.A. MORAVCSIK (eds.), Universals of Human Language, Vol. 1, Method and Theory. Stanford: Stanford University Press. pp. 203-224. 1978.

FERREIRA-GONÇALVES, G \& M. BRUM DE PAULA. A emergência do padrão acentual do português: desdobramentos. In: FERREIRA-GONÇALVES, G. \& M. BRUM DE PAULA (eds) Estudos em Aquisição Fonológica v. 4: 47-62. 2011.

FIKKERT, P. On the Acquisition of Prosodic Structure. Holland: Holland Institute of Generative Linguistics. 1994.

FREITAS, M. J. Aquisição da estrutura silábica no Português Europeu Tese de doutorado, Universidade de Lisboa.1997.

GONÇALVES, S.C.L. Banco de Dados Iboruna: amostras eletrônicas do português falado no interior paulista. Disponível em: $<$ http::allip.ibilce.unesp.br/ iboruna> acesso em 08/10/2014. 2014.

HOFF-GINSBERG, E. Mother-child conversations in different social classes and communicative settings. Child Development,62:782-796. 1991.

KEHOE, M. Truncation without shape constraints: the latter stages of prosodic acquisition. Language Acquisition 8:23-67. 1999.

LABOV, W. \& T. LABOV. The phonetics of cat and mama. Language 54:816852. 1978.

LEE, S. Morfologia e Fonologia Lexical do Português Brasileiro. Tese de doutorado Campinas: UNICAMP. 1995.

LUST, B. Child Language: acquisition and growth. Cambridge: Cambridge University Press. 2006.

MENDES, R. B. Projeto SP2010: Amostra da fala paulistana. Disponível em 
http://projetosp2010.fflch.usp.br. Acesso em 30/03/2015. 2010.

MENDES, R. B. \& L. OUSHIRO. O paulistano no mapa sociolinguístico brasileiro. Alfa. v. 56, n. 3, pp. 973-1001. 2012.

MENN, L. Development of articulatory, phonetic, and phonological capabilities. In: B. BUTTERWORTH (ed.) Language Production, vol. 2. London: Academic Press 1983 p. 3-50.

GLEITMAN, L.; E. NEWPORT \& H. GLEITMAN. The current status of the motherese hypothesis. Journal of Child Language 11. pp. 43-79. 1984.

NITTROUER, S.; M. STUDDERT-KENNEDY \& R. S. MCGOWAN. How children learn to organise their speech gestures: further evidence from fricativevowel syllables. Journal of Speech and Hearing Research 39:379-389. 1989.

PATER, J. Minimal violation and phonological development. Language Acquisition 6:201-203.1997.

PIERREHUMBERT, J. B. Exemplar dynamics: word frequency, lenition and contrast. In: BYBEE, J. \& HOPPER, P. (eds.). Frequency effects and the emergence of linguistic structure. Amsterdam: John Benjamins, 2001. pp. 137157.

PRIETO, P. The Relevance of Metrical Information in Early Prosodic Word Acquisition: A Comparison of Catalan and Spanish In: K. Demuth (ed.) Language and Speech 49 (2):233-261. 2006.

RAPP, C. A elisão das sílabas fracas nos estágios iniciais da aquisição fonológica do português. Dissertação de mestrado. Universidade Federal da Bahia. 1994.

RASO, T. \& H. MELLO. C-Oral-Brasil: Corpus de referência do português brasileiro falado informal. Belo Horizonte: UFMG. 2012

ROARK, B. \& K. DEMUTH. Prosodic constraints and the learner's environment: a corpus study. In: S. C. HOWELL; S. A. FISH \& T KEITH-LUCAS (ed.) Proceedings of the $24^{\text {th }}$ Annual Boston University Conference on Language Development 2000. pp. 597-608.

ROSE, Y. \& C. CHAMPDOIZEAU. There is no innate trochaic bias: acoustic evidence in favour of the neutral start hypothesis. In: A. GAVARRÓ \& M. J. FREITAS. Language Acquisition and Development: Proceedings of GALA 2007. Cambridge Scholars Pub.2008 pp. 359-369.

ROWE, MEREDITH L., DAVID COKER, AND BARBARA ALEXANDER PAN. A Comparison of Fathers' and Mothers' Talk to Toddlers in Low-Income Families. Social Development 13 (2) pp. 278-291.2004

SANTOS, R. A aquisição do acento de palavra no Português Brasileiro. Tese de doutorado. Universidade Estadual de Campinas. 2001 
SANTOS, R. A aquisição prosódica do português brasileiro de 1 a 3 anos: padrões de palavra e processos de sândi externo. Tese de Livre-docência. SP: Universidade de São Paulo. 2007

SCARPA, E. Learning external sandhi. Evidence for a top-down hypothesis of prosodic acquisition. In: A. Sorace, C. Heycock \& R. Shillcock (eds.) Proceedings of GALA'1997 Conference on Language Acquisition: knowledge representation and ruling. 1997

SCHWARTZ, R. G. \& L. B. LEONARD. Do children pick and choose? Journal of Child Language 14:411-418. 1982

STOEL-GAMMON, C. Baby talk in Brazilian Portuguese. Revista Brasileira de Linguística, vol. 3, nº1, pp. 22-26. 1976

VELLEMAN, S. L. \& VIHMAN, M. M. Phonological development in infancy and early childhood: Implications for theories of language learning. In: M. C. PENNINGTON (ed.) Phonology in Context. Luton: Macmillan, p. 25-50. 2006

VIARO, M. \& Z. GUIMARÃES-FILHO. Análise quantitativa da frequência dos fonemas e estruturas silábicas portuguesas. Estudos linguísticos XXXVI (1), pp 27-36. 2007

VIHMAN, M. \& T. KEREN-PORTNOY. The emergency of phonology: whole word approaches and cross-linguistic evidence. Cambridge: Cambridge University Press.2013

VIHMAN, M. \& S. VELLEMAN. Whole-word phonology and templates: trap, bootstrap, or some of each? Language, Speech and Hearing Services in Schools. v. 33, pp. 9-23. 2002

WAUQUIER, S. \& N. YAMAGUCHI. Templates in French. In: VIHMAN, M \& T. KEREN-PORTNOY (org). The emergency of phonology: whole word approaches and cross-linguistic evidence. pp 317-342.2012

WATERSON, N. Child phonology: a prosodic view. Journal of Linguistics. $\mathrm{n}$. 7, pp 179-211. 1971

Recebido em: 08/05/2017

Aceito em: 20/07/2017 